William \& Mary

W\&M ScholarWorks

Articles

$10-1996$

\title{
Theory and Practice at the 'Arabic Org': Digital Technology in Contemporary Arab Music Performance
}

Anne K. Rasmussen

College of William and Mary, akrasm@wm.edu

Follow this and additional works at: https://scholarworks.wm.edu/articles

Part of the Ethnomusicology Commons

\section{Recommended Citation}

Rasmussen, Anne K. "Theory and Practice at the 'Arabic Org': Digital Technology in Contemporary Arab Music Performance." Popular Music 15, no. 3 (1996): 345-65. http://www.jstor.org/stable/931334.

This Article is brought to you for free and open access by W\&M ScholarWorks. It has been accepted for inclusion in Articles by an authorized administrator of W\&M ScholarWorks. For more information, please contact scholarworks@wm.edu. 


\title{
Theory and practice at the 'Arabic org': digital technology in contemporary Arab music performance
}

\author{
ANNE K. RASMUSSEN
}

The synthesizer is ubiquitous on the Arab-American musical scene. Heard at every party, and on every recording, the synthesizer sings the lingua franca of international popular music. While the facade and the body of the synthesizer consist of neutral, slick, black plastic and metal technology, the soul of the instrument, when played by Arab-American musicians, is capable of a completely indigenous, if synthetic, musical idiom. In this article I draw on my experience of six performers of the Arabic 'org', commonly known today as 'keyboards', to present a sketch of a modern musical tradition. ${ }^{1}$

While Western instruments have been enthusiastically adopted and adapted throughout the Arab world, there has been some debate on their suitability for Arab music, particularly their ability to produce the neutral- or 'quarter-tones' of the Arab modes (maqāmāt). The Committee on Musical Instruments of the Cairo Congress of 1932, for example, listed among their concerns the introduction of European instruments into the Arab instrumentarium and, more specifically, the introduction of the piano into Arab instrumental ensembles and music education (Racy 1991, p. 76-7; Fathallah 1992). During the early twentieth century, the piano was practical and popular for the performance and teaching of European music and also for the performance of Arab music in certain modes, for example maqām Nahäwand, a mode that is similar in pitch structure to a Western minor scale (Maloof 1917). ${ }^{2}$ However, several special experimental pianos evolved during the first decades of the century, some of them equipped with extra manuals of keys and corresponding strings that were tuned to the necessary non-diatonic notes of the Arab maqāmāt. ${ }^{3}$ While these curious-looking experimental pianos never succeeded in main-stream musical practice in the Arab world, the electric organ, equipped with levers and dials for 'variant' intonation, achieved an important place in the urban music of the Arab world, particularly Cairo, since its invention in the 1960s (Marcus 1989, p. 243).

Today, synthesizers, with their enormous resources and technical possibilities, have become a standard, if not indispensable, component of Arab music performance, both in the Arab world and in Diaspora communities. As far as I am aware, the only places keyboard instruments are not heard are: firstly, in 
government-supported ensembles of the Middle East; secondly, in concerts planned and promoted by arts or public sector agencies that receive funding from agencies like the National Endowment for the Arts where electronic instruments are taboo; thirdly, in university or conservatory ensembles; and, finally, among a few neo-traditional practitioners in the United States and the Middle East whose recordings serve connoisseurs and 'cross over audiences. ${ }^{4}$ Yet in the unsupervised real-time realm of Arab-American music, synthesizers reign as the loudest, largest, most versatile, most expensive, and most powerful instruments.

With their huge sound systems and lively dance tunes, Arab-American musicians bring to community gatherings an all-encompassing sonic environment that replaces the host culture with the home culture and, perhaps more importantly, facilitates social interaction and personal display though dance. In Arab-American communities musicians are highly valued as culture brokers. Coplan uses the term 'culture heroes' to describe musicians whose status 'appears to depend upon the effectiveness with which, both on stage and off, they supply valued metaphors of cultural identity and change' (1982, p. 121).

At first glance we might situate the synthesizer at the head of the parade towards change as it encourages the fading away of cultural particularities and embraces the generality of cultural grey-out. However, a closer look reveals that synthesizer players offer fodder for social meanings and practices central to the construction of cultural identity. Although wrapped in the international language of rock music (much of which finds its origins in the latest hits from the Arab world), the music performed by synthesizer players constitutes an audio-visual bouquet of the trademarks of homeland (place), tradition (history), and ethnicity (origin), with a patchwork of sounds from the collective past. This article attempts to distill some of the ideas, attitudes and, particularly, questions that surround the synthesizer and its controversial place in Arab music-making. How does the synthesizer adapt to the parameters of Arab music performance and how is synthesizer performance practice shaping Arab musical tradition? How are the physical and cognitive processes involved in playing synthesizers and traditional instruments analogous? How do these musicians learn their musical tradition on a non-traditional instrument? How do keyboard players represent, in musical lines and verbal jargon, the constructs of music theory that make their music, as they might say, 'Arabic?'

The research for this project entails discussion and musical exchange with musicians as well as the experience of their performance in private and public contexts. The musical analysis represented here is the result of a collaboration between myself and the six synthesizer players I know best, rather than from an independent analysis of recordings. I will now also put my subjective, musical self into the picture. Since 1986, when I began researching Arab music, particularly in its manifestations in the United States among Arab-Americans, I have documented patterns of preservation, adaptation, and innovation in musical life. Although intrigued with popular music, I followed the lead of my first teachers of Arab music and of the older musicians, whose values about music I came to admire and later adopt for myself, and never really took it seriously. Like many of my Arab-American consultants, and a good number of the scholars whose works I had read, I saw precipitous Westernisation in Arab music as an aspect of the uneven influence of the cultural hegemony of historical and psychological colonialism. I interviewed the master musicians and tried to absorb their musical 
techniques and world-view through informal lessons on the Arab lute (the ' $\bar{u} d$ ). I rarely did more than visit politely with players of the 'Arabic org', whose presence I saw as a deterrent rather than an asset to the Arab musical mix. My perspective reflected the contemporary Western critical tradition that searches for identities and expressions that are rooted in some authentic culture. As Chambers points out in his essay on the international language of rock music, this nostalgia for rooted identities characterises so much modern cultural theory and critical thought, from Romanticism to Raymond Williams (Chambers 1993, p. 207). My attitude was also informed by my own experience as a jazz pianist who at one time made a laborious and sobering decision not to 'go digital'. ${ }^{5}$ To accept the synthesizer as the dominant and prominent instrument of contemporary Arab popular music was a turning point in my research and may be seen by some as heresy. Yet if we are to document practice as it occurs today, the central role played by the synthesizer in contemporary Arab music performance cannot be ignored.

\section{The Arab-American community}

There is a clear and non-contested border between musicians who played what they refer to as 'authentic' Arabic music for their community and a younger group of musicians who played for a polyethnic audience in the public context of the Middle Eastern night-club (Rasmussen 1989, 1991). The former group, professional musicians who established the musical life of their community in the United States during the first half of this century, placed a premium on traditional Arab urban and folk music. Their community, and thus, their audience, was comprised of primarily Syrian and Lebanese Christians, who emigrated to the United States at the beginning of the century, and their families.

United States immigration quotas, enacted in 1923, slowed Arab immigration to a trickle and by the 1950s and 1960s the Arab immigrant population and their American-born offspring were relatively stable and comparatively Americanised. In addition to playing among themselves and solely for their own community events, Arab-American musicians collaborated with musicians of Greek, Turkish, and Armenian origin in the Middle Eastern nightclub ensembles that peppered the American musical landscape, especially during the 1960s and 1970s. This group of 'night-club musicians' incorporated Western instruments, for example, the electric organ or synthesizer, the electric guitar or bass, and saxophones, or trap drums, as adaptive strategies. The synthesizer, or electric organ, was central to their musical and cultural mélange. One man described his arrangements as complete with the 'necessary chords' so that the music would not be too 'indigestive' to the American audiences. Another went so far as to create a label for his music: 'Ameraba - music with that Arabic flavour, geared to the American ear' (Rasmussen 1992, p. 70 ). Although also used in the popular music of the Middle East, the synthesizer carried special status in the United States where it was a summarising symbol of both modernity and American-ness.

Political and cultural factors have effected a musical re-territorialisation during the past decade and polyethnic ensembles of the past are less common today. The Arab-American community has been repopulated, diversified, and reinvigorated during the past twenty years. Following the eradication of strict immigration quotas in 1965, new populations emigrated to the United States from 
all over the Arab World. Liberalised immigration laws, the infamous American promise of economic opportunity and already established Arab-American enclaves were what immigration scholars refer to as a 'pull factors' for increased immigration. ${ }^{6}$ To compliment such 'pull factors' were a number of 'push factors', including the Arab-Israeli wars (1948 and 1967), civil war in Lebanon (beginning in 1975), continuing warfare in Beirut and South Lebanon, the Iran-Iraq war (1980 to 1988), the Palestinian uprising or Intifadah (which began in 1988 with aftershocks to the present), and the Gulf War (1991) with the continuing turmoil it has generated. Nearly one fifth of the estimated 2.5 million Arab-American population resides in Detroit, Michigan. The Detroit area is thought to be the site of the largest Arab community outside of the Arab world. In addition to a stratum of Syrian and Lebanese families who came to the area nearly 100 years ago, new layers of ArabAmericans enrich the ethnic, religious, and national complexion of this large American sub-culture. At least three important new subgroups characterise the ArabAmerican population of Detroit. The first consists of extended families of Sunni and Shi'ite Muslims from the villages of Lebanon who have resettled in Dearborn, Michigan, a city that is part of the Detroit Metropolitan area. The second consists of Yemenis (also Muslims) from both the North and South parts of what is, at this writing, a tentatively and tenuously unified Yemen. Finally, there is a large population of primarily Chaldean (Eastern-rite Christian) Iraqis, the majority of whom come from the northern villages of Iraq.

The community is self-sufficient in many ways. New immigrants are absorbed into family and business networks and endogamous marriage is common. There is an impressive number of professional musicians as this page from just one of the community's Yellow Pages suggests (see Figure 1). Of approximately 150 professional Arab-American musicians in Detroit, however, there are only two or three nāy players, two qānūn players, a few violinists, perhaps a score of ' $\bar{u} d$ players, and a healthy number of percussionists and singers. Keyboards are the instrument of choice among younger musicians. ${ }^{7}$ Countless Arab-American bands in Detroit and across the country feature one or more keyboard players (each of whom plays two to three different synthesizers mounted on a single stand), a guitar and/or bass player, a drummer on trap drums, one or more percussionists on Arab instruments (including the darabukkah, riqq and daff) and perhaps

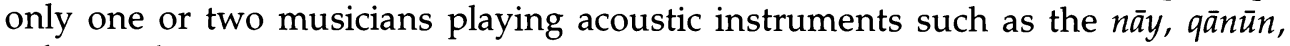
' $\bar{u} d$ or violin.

Arab-American musicians take their lead from their musical brothers in the 'homeland' and, in spite of the paucity of traditional musicians in the community, Arab music in Detroit could not be more 'authentic'. The lyrics, the gestures, the dance, the tunes are all straight from the Middle East. The musical path between the old country and the new world is well-worn. Transnational lines of musical communication, facilitated first by $78 \mathrm{rpm}$ discs in the first half of the twentieth century - and more recently by cassettes, video tapes, and cable television - collect and connect this community. These musicians also take their cue from the international soundscape of technologically driven rock and pop music. Top forty, FM rock, 'lite' rap, Latin dance music, and easy listening soul music is served up intermittently by Disc Jockeys during community parties. Audiences, especially adolescents and young adults, are completely bi-musical and comfortably switch between the music, dance, and language codes of contemporary American and Arab music. 


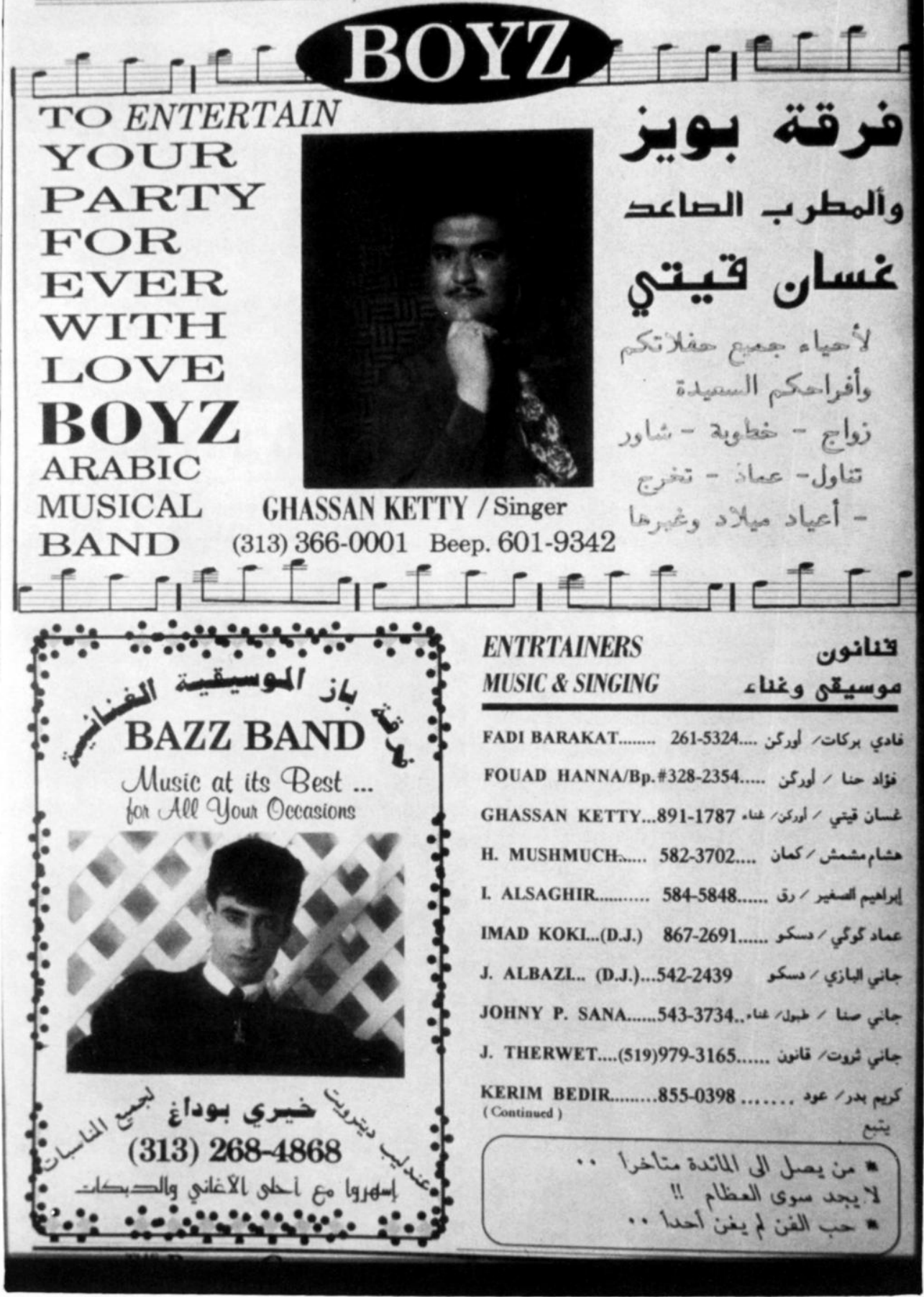

Figure 1. One of eight pages in the 'Entertainer' section from one of many Arab-American Yellow Pages published annually (The Business Guide: Michigan Arabic Yellow Pages 1993-94). 


\section{Digitalising tradition}

Traditional Arab music, known as al-turāth, has always been an elastic category that stretches with regularity to incorporate the new. El-Shawan in her work on Arab music ensembles in Egypt $(1980,1984)$ provides a concise definition of alturāth or 'traditional Arab music' in contrast to 'new Arab music,' or al-jadìd:

during the 1930s and 1940s Arab music producers and consumers used the term al-turath to refer to the 'traditional' repertoire composed and performed approximately up to the 1910s. During the 1960s and 1970s, the boundaries of al-turäth shifted to include the 'traditional repertoire from the 1930s and the 1940s'. Al-turäth stands in contrast with the subcategory al-jadi $d$ which usually designates Arab music that is deliberately and consciously open to non-traditional influences, including musical styles and techniques outside the sphere of Arab music altogether. (El-Shawan 1980, p. 86, quoted in El-Shawan 1984)

Turāth continues to be a flexible category that can incorporate any music that uses the rhythmic patterns, melodic modes, and styles of composition and performance that are the hallmarks of traditional Arab music. Today, in fact, the boundaries of al-turāth have shifted again to include some compositions of the 1960s and 1970s originally thought of as al-jadīd (new) but that are now referred to as al-turāth (traditional) by contemporary performers (see also Schuyler 1990a, 1990b).

How is tradition being digitalised and maintained in the Diaspora where notions of tradition are vitally important? How is instrumental practice in Arab music being transferred from a small ensemble of acoustic instruments, wherein individual nuance and soloistic textures are premium, to an even smaller ensemble that consists of several keyboards and a couple of token instrumentalists? A profile of two musicians, both keyboard players, will suggest broader issues that extend through this musical sub-culture, and perhaps to other musical cultures, where the adaptation of international technology goes hand in hand with the procreation of new, culture-specific musical practices.

Abe Abbas graduated from high school in the Spring of 1994 . He attends a college close to home so that he can continue to perform with his father Abdallah Abbas, a singer and ' $\bar{u} d$ player of Syrian and Lebanese parents (see Figure 2). Abe plays a Korg $\mathrm{O} 1 \mathrm{~W}$, an instrument that offers the possibility of variable tuning and a number of 'ethnic sounds' that can be altered and stored. He also plays a Yamaha PSR 6, an instrument that comes complete with built in samples of Arab instruments and rhythmic patterns. Abe's Yamaha is assembled in Kuwait and distributed through community networks in the United States. ${ }^{8}$ He combines these two instruments with a drum machine on which he programs the Arab rhythms that provide the sonic canvas upon which the rest of the music is layered. Abe performs with his father, a singer who used to also play the ' $\bar{u} d$ in the traditional manner until the time when audiences' tastes began to demand a 'stand-up singer'. ${ }^{9} \mathrm{~A}$ drummer (playing Arab percussion instruments), and sometimes a nāy player, accompany this duo on their gigs. Thus they travel as a trio or, sometimes, a quartet.

Abdallah and his son and partner, Abe, see changes in musical practice as completely audience-driven. Artistic innovation and aesthetic change originating among audiences rather than among musicians has been a common theme in the discourse of Arab-American musicians for some time, at least since the beginning of my fieldwork. According to this father and son team, audiences want to dance all night, they want fast music, and long sets that have no pauses between songs. 


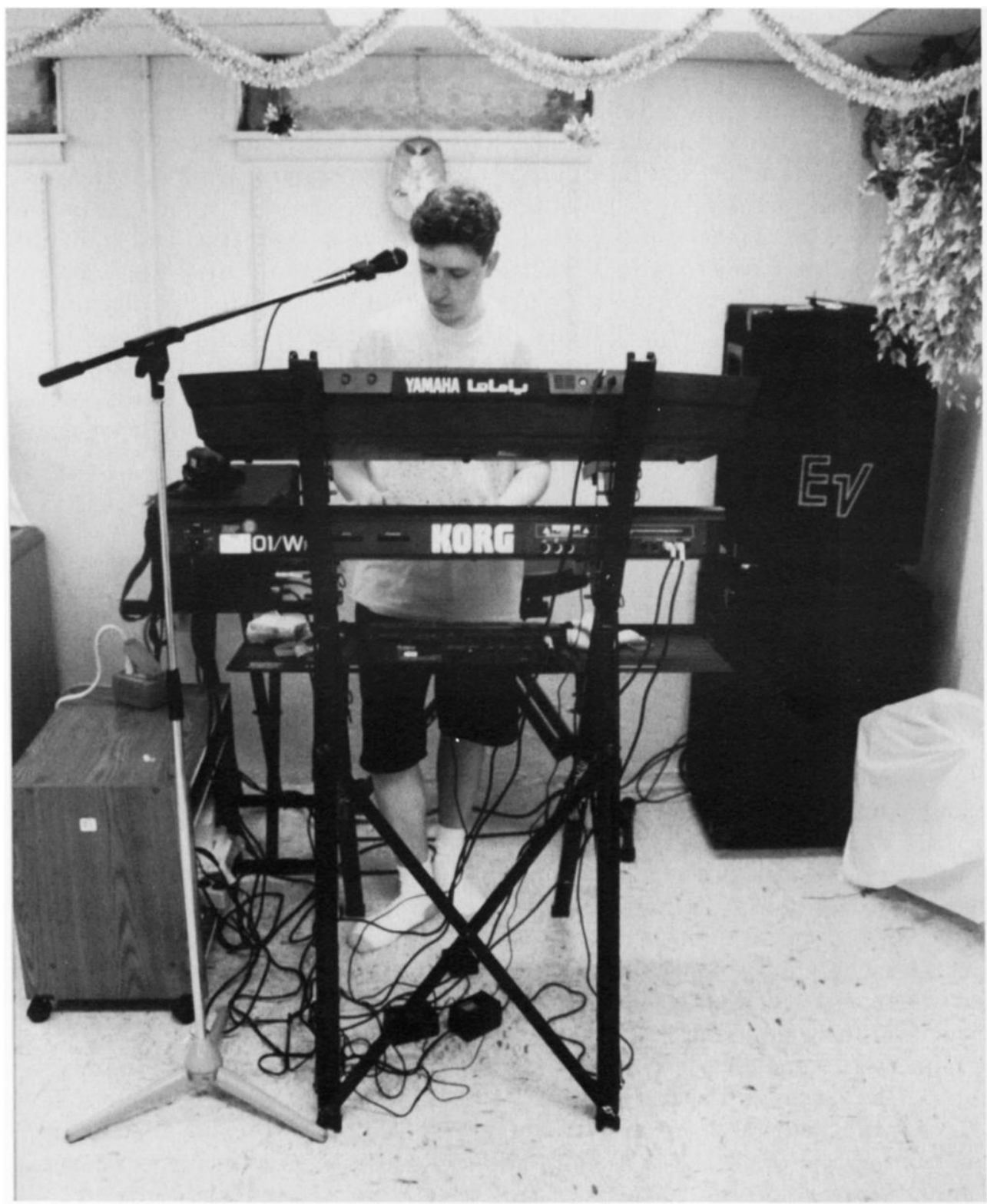

Figure 2. Abe Abbas and his keyboards in the Abbas' basement, Dearborn, Michigan.

They want the music to be loud and lively. Abdallah understands audience demands. 'You are more relaxed after you dance,' he explained to me. We discussed how dance is social, cathartic, and fulfilling, in comparison to listening, which can be passive and intellectually demanding. Abe works hard to smooth out the segues in their sets so that hardly a second of silence goes by. Music is their sole profession at present and it is important that they be responsive to the demands of contemporary audiences.

Abdallah has a matter-of-fact, historically informed perspective on the contemporary music scene. He was also born in the United States but grew up a 
participant in an earlier era of Arab-American musical activity. Abdallah performed and learned music with virtually all of the 'old timers' in the United States and is, at heart, a self-defined practitioner of tarab music: traditional urban music that foregrounds modal exposition, development, and modulation in both singing and playing, the juxtaposition of various rhythmic patterns, attention to the poetry of songs, and the art of instrumental and vocal improvisation. The tarab repertoire that forms the foundation of Abdallah's musicianship places a premium on the musical aesthetic of saltannah, a kind of euphoric state in both artist and audience. Although music is their work, Abdallah and Abe talk about their music as art. While the younger is a vessel for all of his father's knowledge, particularly of modes and repertoire, he is the first to admit that he likes the latest thing 'anything with keyboards and drum machines' (to which Abdallah responded in a friendly tone 'I give him that right'). During a long afternoon in the Abbas' basement rehearsal space, Abdallah and Abe demonstrated with their keyboard equipment why, in Abdallah's words 'we couldn't live without it' ${ }^{10}$

\section{Abe Abbas' one-man band}

To give an example of how he combines his keyboards and plays them simultaneously like a one-man-band, Abe plays part of a popular tune. First he chooses the timbral setting he wants on one keyboard; a custom tailored 'patch' he created called 'Abe Strings' appears on the VDU (visual display unit). Then he sets the rhythmic pattern (maqsüm) into play on another keyboard (such actions are indicated by an asterisk $\left(^{*}\right)$ in the transcription, see Example 1 ).

The rhythm now in motion, Abe begins to play a melody line in maqām Hijāz with his right hand (scale in ascending and descending order of pitches: $\mathrm{D} \mathrm{Eb} \mathrm{F \#}$ G A B1/2-flat C D C Bb A G F\# Eb D). His left hand moves deftly to accomplish a number of ancillary functions. With it, he reprograms the manual to change the instrumental timbre of the melody line after each eight-bar phrase. In what we might label the ' $\mathrm{B}$ ' section of the tune, the melody is based in the upper tetrachord (jins) of the mode and features a B 1/2-flat in an ascending gesture and a B flat in the cadential descending gesture. Abe's left hand reprograms the keyboard while playing to produce the appropriate changes in intonation. Following a repeat of the tune, Abe transitions into a few moments of taqāsim 'ala al-wahdah or improvisation on the beat: the rhythmic pattern maqsüm is reinforced with an alternating octave vamp with his left hand, as it might be played on the ' $\bar{u} d$, for example, and the right hand plays a non-metric melismatic improvisation. Just prior to his resumption of the 'head' or 'top' of the tune he punctuates his taqūsim with a couple of repetitions of a D major triad outlining the rhythmic pattern maqsüm (see Example 1). ${ }^{11}$

In résumé, Abe demonstrated in this two minute solo: firstly, his ability to perform as a large ensemble, a rhythm section, and a solo instrumentalist playing an improvisation all in the same musical moment; secondly, the use of various instrumental timbres for the solo line; and thirdly, the way in which intonation can be adjusted during performance. That afternoon, our most interesting discussions focused on the topic of intonation and the ability to improvise idiomatically within the system of the Arab maqāmāt.

Today's digital technology offers limitless tunings and possibilities of intonation. Many synthesizers contain software that features 'global' scales, with their 
Example 1. Abe Abbas' One-Man-Band

Drum machine: Maqsum, continues throughout
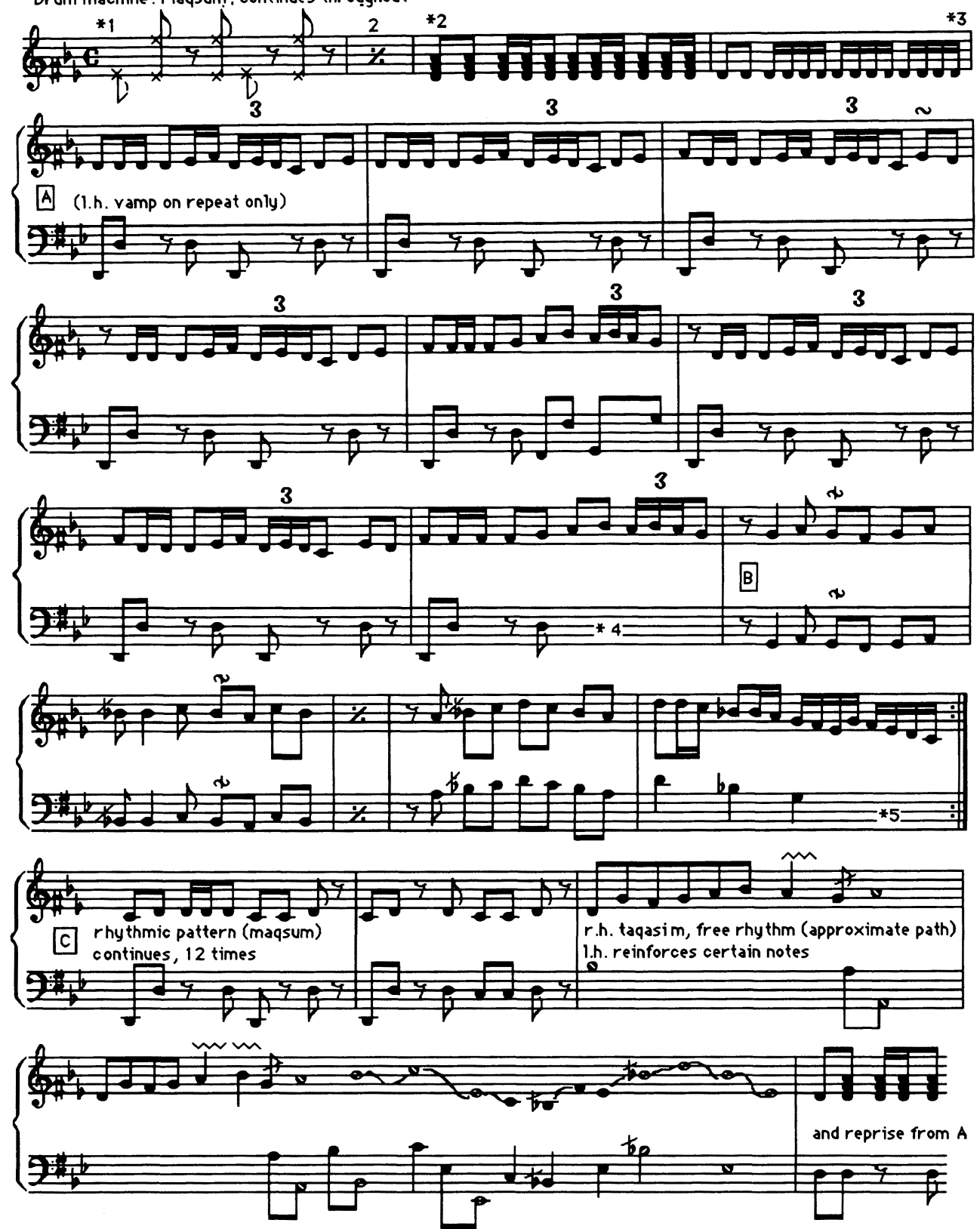

Form of tune: Introduction, A: first section of tune, B: second section of tune in the upper part of maqām Hijaz, C: taqāsìm 'ala al-wahdah (non-metric improvisation in right hand over metricvamp in the left hand).

* Indicates left hand moves to make a change in instrumental timbre or intonation of a particular note.

${ }^{*} 1$ : Left hand sets rhythmic pattern (maqsüm) in motion.

*2: Left hand selects 'horn' sound.

*3: Left hand selects 'Abe Strings' sound.

* 4 : Left hand selects 'rich strings' sound and changes intonation of Bb to B1/2-flat (played with B-natural key on the keyboard). Both the Bb and the B1/2-flat are available on the keyboard for the remainder of the performance.

*5. Left hand selects 'Abe Strings' again for reprise of section A of the tune. 
characteristic intonation, from all over the world. Available software might identify these so-called 'Global' scales with such terms as 'Arabic 1', 'Arabic 2', 'Arabic 3', 'Turkish 1', 'Turkish 2', 'Javanese 1' and so on. A player can scroll through their options printed on the display screen (VDU, see above, or LCD for liquid crystal display) until they find the one that sounds right. Digital synthesizers also offer the option of creating your own tunings by shaving off or adding even a few cents to any note. In practice, this process is similar to reducing your original on a Xerox machine: you press a button until the desired percentage of reduction appears on the display and then make your copy. With the latter process a musician cannot simply dial a scale; they need to know which notes to 'detune' and by how many cents. ${ }^{12}$

It seems that with this research we are in a position to investigate not only the technical capabilities musicians are exploiting but how the experience of using this technology is similar or different from the experience of traditional music performance. As was exemplified in the first performance vignette, Arab music can require frequent shifts in intonation. Modulating 'on the fly' is part of the essence of Arab music, both in precomposed songs, and in improvisation. Thus a keyboard player, or any musician, must not only know how to 'detune' (as one musician put it) notes of a particular maqām, he must also know how to retune those notes and 'detune' others once 'in flight'. A musician who performs on an acoustic instrument must be able to conceptualise intonation and modulation in his mind's ear. On an aerophone or chordophone, such as the $n \bar{a} y$ or the ' $\bar{u} d$, the correct fingering and/or breath pressure will produce the right note. On the qānūn, a performer adjusts small levers ('urub-s or mandal-s) that fulfil the same function as a finger on the neck of a stringed instrument: the levers lengthen or shorten the string.

\section{Variant intonation and modulation}

The thought processes and performance practice of qānūn and keyboard players may have some parallels. Retuning during performance is a major technical challenge of traditional $q \bar{a} n \bar{u} n$ players. Seconds before he plucks an accidental note or changes a pitch, a $q \bar{a} n \bar{u} n$ player prepares the string by flipping up or down small levers ('urab-s or mandal-s) with the left hand as he continues the melody line with the right. When the left hand is not busy adjusting the tuning it 'ghosts' (author's term) the melody an octave below or helps to create a tremolo or an ornament. Like the qānūn player, a keyboard player must anticipate a change in intonation, dial up the note on the screen, flatten or sharpen it, all with his left hand, before he plays it with his right. Unlike a the qānūn player, the keyboard player's move will alter the note in question across the keyboard, in every octave, while the $q \bar{a} n \bar{u} n$ player will only alter one note at a time. ${ }^{13}$ To demonstrate the ease with which he could improvise within the system of Arab maqāmāt during our discussions, Abe Abbas performed an extended taqāsīm during which he modulated several times. The discussion revealed a number of significant points.

'What makes it (the keyboard) really, you know, popular with the Arabic people is that is has the global tuning, which is the quarter tones,' Abe explained. 'Let me get into a global sound, for example . . .' Abe dials up the right combination on his keyboard. 
Example 2. Variant intonation and modulation. The scales of maqām Huzām and maqām Bayyāti Sol (on G).
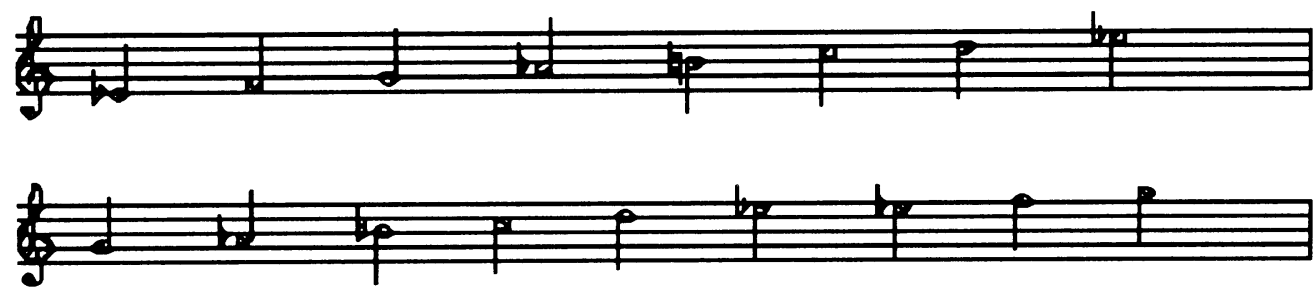

'Most keyboard players they know one song and that's it. Taqāsimm? No! (Now) you can listen to Abe play any maqām, maqam Rāst . . . whatever he wants!' Abe's Dad proudly boasts.

Abe begins his improvisation in a mode I identify, and he confirms as maqām Huzām (E1/2-flat F G Ab B C D E1/2-flat). He prepares for modulation from maqām $H u z \bar{a} m$ by anticipating tuning changes in the upper part of the scale (G A1/2-flat $\mathrm{Bb} \mathrm{C}$ ) and programming or selecting them with his left hand while his right hand continues with the melody. When it's not busy 'retuning', his left hand plays a skeleton of his right hand melody or 'ghosts' the melody an octave below. As he accomplishes modulation after modulation, we identify them.

'Bayyāti?' I query, 'where did you just go?'

'Bayyāt Sol (G),' Abe confirms.

'Aha!' I exclaim. 'So that's what you switched, you made the A half-flat, you switched the A, right? You pulled it up on the screen . . .'

'. . . and then I tuned it to 50 cents,' Abe completes my sentence.

'Cool!'

Abdallah, who seems impressed with my knowledge of the maqām system and my ability to recognise various maqāmāt and variant intonation reminds me, 'Maybe you know this, the switching shouldn't be noticeable, you should go right into it smoothly.' (See Example 2.)

Abdallah takes pride in his son's talent and ability to modulate imperceptibly. They, as well as other keyboard players, also pointed out that a synthesizer offers the possibility of transposition, which is invaluable for today's singers who might only be comfortable singing in certain ranges or keys, or more challenging still, who might not even know what key it is that they do sing in. ${ }^{14}$

How standardised has practice in the domain of intonation become among keyboard players? Although somewhat arbitrary, the '50 cent quarter tone' seems to be the norm. Nevertheless the dust has not completely settled around this theoretical construct of the 24-tone scale that, first widely publicised in Mashaqah's treatise of 1840 (Marcus 1989, pp. 164-9), now finds a scientific, practical incarnation in the synthesizer. The limitless possibilities of any machine equipped with microtuning would allow for minute variations in tuning; theoretically this feature could allow for different versions of non-diatonic, neutral tones. For example the E1/2-flat of maqām Rāst could be set a bit higher than that of maquam Bayyati, as musicians and theorists have sometimes insisted is the case (Marcus 1989, p.17888). Abdallah, for example, explains that a neutral tone or half-flat is about ' 52 and a half cents' higher than the regular flattened interval but that the 50 cents on the Korg is 'certainly acceptable'.

For those who cannot or who do not want to bother with this multi-step process of descending through the branched system of the hierarchically organized 


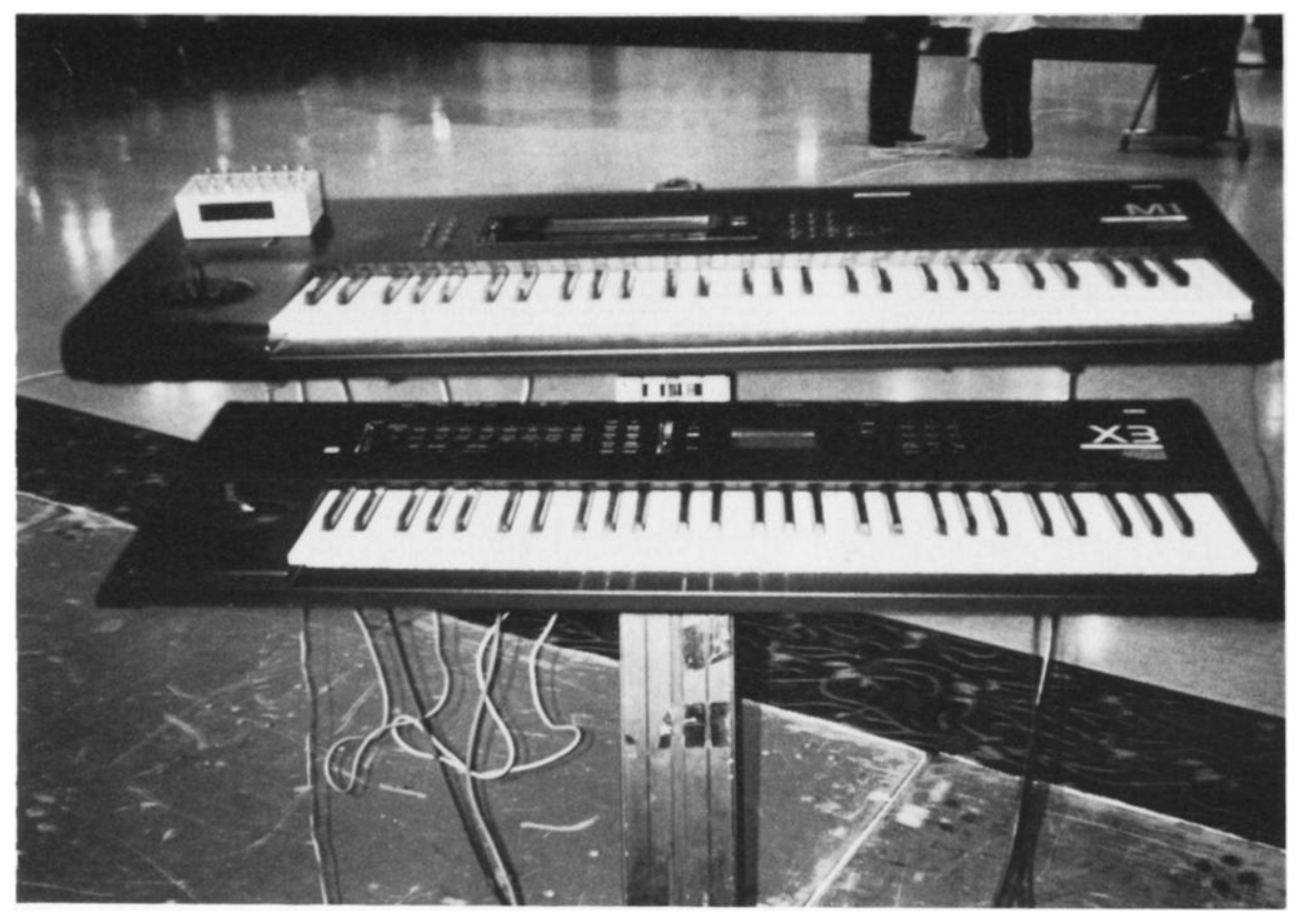

Figure 3. Ghassan Shaito's keyboards complete with 'the box' designed by Tom Abraham, community wedding, May, 1995.

computer commands, there is what musicians refer to as 'the box'. About the size of a small tissue box, this device has twelve levers, one for each note of the piano. By flipping forwards a switch (for example, the $\mathrm{Eb}$ ), every $\mathrm{Eb}$ on the keyboard is altered to E-neutral or half-flat. ${ }^{15}$ 'Box' inventor Tom Abraham, an electrical engineer and keyboard player in the Detroit Arab-American community, estimates that there are about 25-30 musicians who use his box in the country. Using MIDI technology, the box eliminates the three or four step process of calling up the note on the VDU and 'detuning' it by 50 cents. One Detroit keyboard player, Ghassan Shaito, extols the virtues of Abraham's box. When he grew up in Lebanon he played the music of the internationally popular rock group Santana. Ghassan learned Arab music in the United States as a 'second language', and he was playing all the Arab maqāmāt before he knew their names or how they worked. He told me that at first he was 'scared' to go from one mode to another, but later, with the 'box' it became second nature, 'like shifting gears on a car' (G. Shaito, personal communication, 10 July 1994) (see Figure 3).

As one long-time friend in the community quipped, Abraham's one-step box 'does the sex change on the organ'. Obviously this comment was made in jest, yet the perceived 'specialness' of the Arab maqām system provokes such a radical analogy. Musicians have repeatedly led me to believe that it is necessary to be born into the tradition, that you have to 'feel the quarter-tone', that these special 
notes cannot really be measured, explained, or taught. When I play for them, and especially if my playing is idiomatic and in tune, they are astonished to the point of disbelief. That the dial-a-scale capabilities of the keyboard supply easy to follow, never fail, recipes for acceptable intonation, without any prerequisites regarding birth or feeling, is one of the ironies in the bundle of social meanings harvested in the course of conversation with musicians and audiences.

\section{Instrumental timbre and sampling technology}

While most players I have visited perform using instruments manufactured by Korg, numerous other manufacturers are catering to the 'ethnic' market and that abounds with a plethora of adaptable machinery (both hardware and software) too varied to enumerate here. Many of these synthesizers come with 'factory presets' or 'patches' of sampled sounds that range from the Indian sitar to the Israeli shofar on the 'authentic end' of the spectrum to 'groan drone' and 'Akhmir's Tent' under the category of 'synthetic blends' (Proteus/3 Operation Manual, 1993).

Some keyboard players buy their equipment new but musicians also recycle equipment, both hardware and software, within the community, so that some of these instruments come already tailor-made for the performance of Arab music. In order to get the most authentic sounds from 'over there', one young New England musician brings formatted discs to concerts of musicians touring from overseas and copies the custom-tailored patches of Beirut keyboard players. ${ }^{16}$ Among the most important and perhaps standard elements of performance practice is to be able to use and alter the various factory presets. One musician explained that his instrument is high-powered but that the sounds coming from the company are not 'suitable for each culture'. 'Even people of the same culture have different tastes,' he elaborated. The preparation of a synthesizer is 'like decorating your house. Every one has the same idea but they all do it in different ways' (W. Mustafa, personal communication, 3 July 1994). All the keyboard players interviewed echoed this sentiment. Altering the frequency (pitch), wave shape (timbre), and envelope (nature of the attack and decay) and being able to variably split your keyboard or keyboards to create an ensemble of sounds are necessary tricks of the trade.

\section{'Organised' music}

Another consultant for this project, who is a model of ingenuity in the emergent Arab-American keyboard tradition, is Majid Kakka. Majid is the lead singer and instrumentalist of The Bells Band, the most popular Iraqi band in Detroit, if not the United States (see Figure 4). Born in 1959, he came to the United States in 1981 with his family after brief sojourns in Italy, Yugoslavia and Greece. With keyboard, computer, and digital sampling equipment worth about 80,000 dollars in the basement studio of his house, Majid Kakka is an exemplar of modernity, professionalism, and, as he calls it, 'organised music' for the many less experienced bands in town.

Although Majid attended the Institute of Arab Music (Mahad il-naghmāt il-'Arabiyyah) in Baghdad he has been involved with Western rock and roll since he was a child. While growing up, Majid lived on Baghdad's embassy row where he bought an electronic keyboard and later his first guitar from hippies who were 


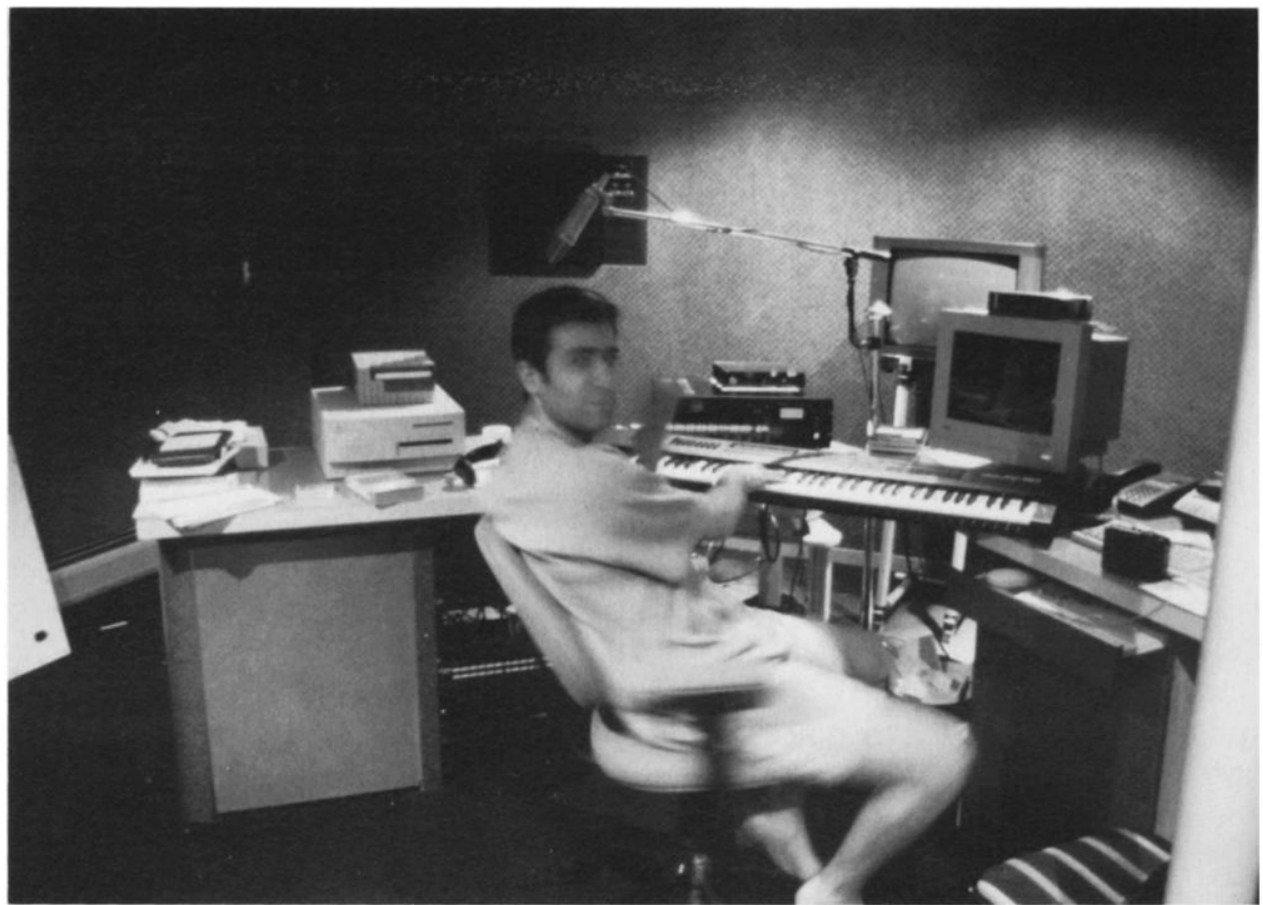

Figure 4. Majid Kakka in his basement studio, Southfield, Michigan, July, 1994.

given safe haven outside of the English embassy for a few weeks. He reminisced 'I had a red Gibson guitar and a little red compact Farfiza keyboard from Italy and I thought I had the whole world.' At the age of 11, Majid, with his brothers, started The Bells Band. The group played the music of The Rolling Stones, The Beatles and Black Sabbath.

Ten years later when he emigrated to the United States, he was unable to succeed in rock and roll. 'Believe me,' Majid insisted, 'we were very professional with the heavy metal music, but we couldn't get [a] job. Maybe it was the black hair we got. Maybe it was because we were foreigners. All they wanted was blondies for Heavy Metal.' To counterbalance his rejection from the American musical mainstream, Majid found a huge community of Iraqis starved for the music they never heard: music from 'back home'. When he introduced his 'organised music', Majid explained, 'there were no more jokes'. He put modern Iraqi Chaldean music on the map. The Bells Band features Majid with an array of keyboards and two 'drummers' who play digital pads.

Majid has 500 megabytes of information in his keyboard with over 2,500 samples that he has taken himself. He has sampled all of the older master musicians in town, that is to say, the handful who actually play traditional music on acoustic instruments. He boasts that he has all of them (the musicians ) in his keyboard and can conjure them up with the push of a few buttons. Majid sees his work as a business. References to 'marketing' his music and his 'high end digital samples' were frequent in our many hours of conversation.

I watched The Bells Band, impeccably dressed in black tuxedos, entertaining at the party after a wedding. Although Majid stood behind a set of three keyboards, mounted on a stand and next to a four-foot stack of computerised compon- 
ents, he was performing a single melodic line within a range of about a perfect fifth. Appearing on the VDU was the word mijwiz, a double-piped, single-reed folk aerophone common to the Arab Levant. The nasal, piercing timbre of his sampled mijwiz, as well as the monophonic, melismatic line and small range of his melody, are a relatively idiomatic representation of this folk style. A line dance called the dabkah was danced by the crowd, a well-heeled group of celebrants including non-Arab-Americans from the groom's family, the Arab-American relations of the bride (whose Iraqi grandfather immigrated to North America in 1905) and all of their friends.

Majid was flanked by the two other members of The Bells Band, both wearing cordless headset microphones and playing digital drum pads with trap set sticks. One of the 'drummers' had a cymbal mounted on his 'rig', which was the only non-electronic instrument on the stage. To compliment Majid's funky, folky solo line, one of the drummers played a dazzling solo on one of his pads that produces the sampled sound of the zambur (also kashba or kishba) (Qassim Hassan 1984, p. 423). Indigenous to the rural regions of Iraq, and traditionally played by Gypsies (although later urbanised), the zambur is a narrow, single-headed drum that produces a high pitch and is played in a style that features rapid-fire soloistic spurts of rhythm (as opposed to outlining a rhythmic pattern). ${ }^{17}$

The mijwiz and the zambur are instruments that very few people play but whose sound is indispensable to contemporary practice with its nostalgic emphasis on folk music and dance genres. At Arab community events, the sound of the mijwiz is practically inseparable from the robust movement of the dabkah; the music and dance are a 'packaged deal'. The sound of the mijwiz, or the double reed oboe, the mizmar or zamr, with their reedy, nasal, simultaneously obnoxious and intoxicating persistence, their endless, repetitive, non-diatonic melodic lines spun out (traditionally with the technique of circular breathing), has always been part of the collective soundscape. Although in the United States the instruments themselves have been uncommon throughout the century, their sounds have been invoked with special tuning and techniques on the violin (Rasmussen 1991, p. 226), reproduced on the sax (Rasmussen 1992, pp. 71, 74) or, as is predominantly the case today, sampled or approximated on the synthesizer. When the the timbre, style, and groove of these folk instruments are in reinvented performance, digital musicians evoke the ethos of tradition and celebration. ${ }^{18}$

\section{The synthesizer and contested modernities}

When queried about keyboards, antithetical sensibilities abound among performers and audiences of the Arab-American scene. Varying opinions about the synthesizer reveal an instrument with multiple identities. Four excerpts from the discourse of musicians and community members illustrate the point.

First, we return to the seasoned perspective of Abdallah Abbas, the senior member of the father/son duo profiled at the beginning of the article:

In the United States, we couldn't live without it. A keyboard player can sound like a full orchestra, all of the particular timbres of the Arab firgah [orchestra] are possible with the push of a button. (8 July 1994)

Abbas underscores an important point. With its orchestral capabilities the synthesizer invites the orchestration and arranging techniques of an important repertoire 
of twentieth-century urban Arab music. Since the expanse of the traditional three to five instrument takht ensemble to the larger and more catholic firgah, and particularly with the compositional techniques advanced by Egyptian composer Muhammad 'Abd al-Wahhāb, a variety of instruments may be used sparingly for little solo spots within a composition. Thus, a very exposed electric guitar line, or accordion solo may, after its prominent moment in the sonic spotlight, disappear into the orchestral mix for the rest of the performance. In addition to creating the aural illusion of Arab traditional instruments such as the qannun, ' $\bar{u} d$, or $n \bar{a} y$, the synthesizer puts an orchestra of soloists at a player's fingertips without the hassle of paying the piper or rehearsing the band.

Second, we hear from an Arab-American writer of international repute who reflected upon the topic in an e-mail message he sent to me:

Another aspect, which interests me the most is the death of the traditional instrument player and the emergence of the synthesized one-man-band. The synthesizer is the dubious contribution of Egyptian trashy musicians of the late seventies. How significant is it?' (12 September 1994)

This assessment of the introduction of synthesizers into Arab music resonates with the sentiments, even if involuntary, of many intellectuals and ethnomusicologists. That the synthesizer be the 'dubious contribution' of 'trashy musicians' aligns modern practices with the cheapening, dilution or abuse of tradition. I am reminded of my vantage point at earlier stages of my fieldwork and training and my innate drive to find identities that were framed by performance and rooted in authenticity (see also Chambers 1993). The maintenance of tradition and the musical ways of the old world may, however, be an option that is not only unavailable to the average 20-year-old Arab-American male, but something seen as completely undesirable and oppressive (see also Coplan 1991, pp. 36-40). To see the situation from a different perspective, the precise imitation of keyboard players from Lebanon and Egypt may be the most traditional and authentic gesture that Arab-American musicians can make.

The third testimony comes from Majid Kakka, who, responding to my question, muses about opening a music school in the future:

This school's gonna be unique. The school will be teaching students the Arabic music through the digital era. The musicians will learn through the digital keyboard but not the old instruments. Who would be interested in playing Arab instruments anyway? If given a choice between the guitar and the banjo, which do you think an American kid would choose? He'd say: 'What the hell am I going to do with a banjo? American folklore music? No no, I'll play the guitar.' (7 July 1994)

Majid Kakka presents a completely relevant American analogy. The relatively few young Americans who do play the banjo are more likely to be involved in musical fusion and revival than they are in directly carrying on the musical practices of their grandparents. This speaker is not interested in abandoning his tradition. On the contrary, with his efforts to market his 'high-end samples' and his plans for a Arab music CD ROM project, he seeks to bring his music to the widest possible audience through the most modern and technologically advanced means. Majid Kakka's words illustrate the multivalence of musical symbols in public performance. Musicians bring all kinds of symbols to their audiences and the music they provide is an important tool in the construction of identity, particularly in the Diaspora. Performance is public display and instruments, because they are items 
of material culture, connote explicit identity in the same way that skin colour or hair texture do. What you play shows others in a positive, non-confrontational way who you are. Standing behind a three-tiered set of keyboards proclaims economic security and international savoir-faire. The ability to manipulate an instrument such as the Korg $\mathrm{O} 1 \mathrm{~W}$ is an indication of musical literacy that is accompanied by irrefutable prestige.

Finally, in conclusion, a word from one of the most prominent musicians of Arab heritage in the United States:

I'm sorry to say it - in Lebanon we have a saying 'Al-hamar bidu al-bayyanu' - 'the Jackass plays the piano'. [On the synthesizer] the notes are all right there - all you have to do is press your finger down 'tap, tap tap'. With a violin, or an ' $\bar{u} d$ or a $n \bar{a} y-$ you have to find the tune with your fingers. (4 July 1994)

This musician, who actually uses a synthesizer in his band, believes that the instrument is useful for the imitation of the saxophone or accordion. He maintains, however, that it is no good in place of the ' $\bar{u} d$ or $\bar{n} a y$. During our conversations, he suggested that acoustic music is an period of dormancy and that its return to the forefront is inevitable.

The first three speakers voice the way things are; the last voice is perhaps the most prophetic, foreshadowing the way things might be. If the actors in this musical sub-culture are indeed members of an international musical community that speak the global language of rock and rop, the revisionist move of Western rock and roll practitioners to 'unplug' may be forthcoming on the Arab music horizon. ${ }^{19}$ The final speaker, who predicts the imminent return of real instruments, might well agree with one of the engineers interviewed for Porcello's research (1991) on the practice and ethics of digital audio-sampling: 'I have less bands coming in who want sequencing or sampling, because it has no feel. If it moves you, it moves you. If it doesn't, it's probably sampled' (Brewer [pseudonym] quoted in Porcello 1991, p. 75). Even the most knowledgeable keyboard players will reveal their digital disguise because their instruments simply are not capable of so many of the idiosyncratic qualities and imperfections of acoustic instruments and the kinaesthetic limitations of the human beings who play them. The momentary double stop of the violin, the sympathetic resonance created by an echoing lower open string on the ' $\bar{u} d$, the burst of energy in a musical phrase of the mijwiz that follows strategically placed technique of circular breathing are all shades of musical colour that make Arab music affective, or, in Brewer's words, 'moving'. If 'unplugging' occurs perhaps the synthesizer will have served as a kind of incubator, storing acoustic sounds for their eventual renewal by a new generation of inquisitive instrumentalists.

The enthusiastic embrace of the synthesizer may be explained by a number of factors, in particular, access to capital in the United States, the experience of rock and pop music on the part of contemporary musicians, and the desire to play a technologically sophisticated instrument of international repute. Although representative of incontestable change, the synthesizer is also a repository of the illusive rooted identities that scholars and community members inevitably crave. Keyboard players curate, collect, and store in their digital museums an array of sonic artefacts that may be called forth and set into action in the context of public ceremony and celebration. Such sonic artefacts are represented acoustically in the sampled timbre of the Arab ' $\bar{u} d$, the horn patch copied onto disc from a touring 
Beirut musician, or in the idiomatic style and idiosyncratic intonation of a taqāsim in the maqām Huzām. Sonic artefacts are also referenced by key words like 'Abe Strings', 'mijwiz', and 'zambur', that appear on the VDU in the familiar digitised script that characterises so much of our graphic visual world from computer screens to alarm clocks. Played for Arab-American celebrants by tasteful artist or capricious amateur, the synthesizer conflates the ancient and the modern and folds them into the moment of performance and experience.

\section{Endnotes}

1. The term org is from the French 'orgue' for organ and was originally adapted by Arab musicians to refer to the electric organ or piano. While many have contributed directly and indirectly to my work over the past several years, the keyboard players who advised me for this project include, but are not limited to, Abe Abbas, Majid Kakka, George Musally, Walid Mustafa, Ghassan Shaito, Sami Yusef and Wa'el Rami. The musicians profiled have reviewed an earlier draft of this work. I also thank Martin Stokes for his thoughtprovoking commentary on my work. I do, however, accept responsibility for all of the opinions and ideas expressed herein.

2. An excellent example of the adaptation of Arab music for piano are the several volumes of sheet music by Syrian-American pianist, composer, publisher, record producer and ensemble leader Alexander Maloof. His five volumes of Oriental Music for the Piano include a number of traditional Arab songs originally in maqam Nahawand that are translated into a minor key and harmonised. A recorded example of his music is forthcoming on the Rounder label.

3. Fathallah's article (1992) on the recommendations of the 'Instrument Committee' at the Cairo Congress profiles some of the concerns and conclusions of musicians and scholars with regard to the adoption of piano and other European instruments such as the 'cello and bass. She also recognises musicians, such as Sayyid Darwish or Muhammad 'Abd alWahhāb, whose use of Western instruments in their compositions and performances was a much more decisive influence in regard to this issue than the deliberations of scholars at the Cairo Congress. The proceedings of a conference on the Cairo Conference of 1932 entitled Musique Arabe: Le Congrès du Caire de 1932 includes a number of photographs of experimental instruments presented at the conference, including fourteen pianos with extra keys and strings. See Vigreux's contribution to this extensive volume on the Cairo Conference (1992, pp. 347-426).

I am grateful to Scott Marcus for our discussions about early electronic keyboards and their ability to reproduce quarter tones. See also Bakan et al. (1990) for an organological investigation of this truly international instrument.

4. For example, Simon Shaheen's Turath (1991) is marketed more carefully to the international music buff than it is to the Arab-American community.

5. When I moved to Los Angeles for graduate school in 1985, I investigated the possibility of upgrading my piano for a synthesizer with MIDI capabilities. I had earned extra income as a singer and pianist for a number of years and after having arrived in Los Angeles was repeatedly asked by potential patrons if I had a drum machine or electronic keyboard. I eventually decided not to 'go digital' due in part to my new interests in studying the ' $\bar{u} d$, in part to a sense of intimidation at the thought of the investment of time and money to incorporate such technology into my musical life, and in part due to my purist preferences for acoustic 'unplugged' music.

6. I take the notions of 'push and pull factors' of immigration from Michael Robinson and his lecture 'Patterns of immigration, ethnic community and contemporary indentities', International and Area Studies Summer Institute for Educators: Middle East Seminar, University of California at Los Angeles, 1 August 1994.

7. Arab musical instruments include: the ' $\bar{u} d$, a fretless lute with 11 strings; the qānūn, a trapezoid-shaped zither with 72 strings in triple courses; the nāy, a reed flute (to play all modes, several sizes are used); the violin, tuned bottom to top: G-D-g-d; the riqq, a 
tambourine of 10-11 inches with heavy brass cymbals; the darabukkah, a ceramic, vaseshaped drum with one head; the daff, a frame drum, 12-18 inches in diameter; and folk instruments like the mijwiz, a single-reed, double piped 'clarinet', the mizmar, a doublereed 'oboe', and tabl baladi, a double headed bass drum usually played with the mizmar.

8. Although Abe speaks colloquial Arabic he has never learned to read and write the literary Arabic language fusha. Abe was enthusiastically amused at my ability to read the Arabic words that label each of the stops or buttons on his Yamaha keyboard from Kuwait. On the Kuwaiti Yamaha there are buttons that: change the instrumental timbre, for example qānūn, nāy; set various rhythmic patterns into play, for example maqsūm, samá'i thaqìl; effect the intonation particular to the Arab modes or maqāmāt, for example Bayyāti, or $\bar{R} \bar{a} s t$.

9. Abdallah was a singer-' $\bar{u} d$ player as were many singer, instrumentalist, composers of the Arab world (for example Farīd al-Atrash or Muhammad 'Abd al-Wahhāb). His reference to 'a stand-up singer' reflect audiences' expectations for an entertainer who can roam freely among the dancers while singing, gesturing to the audience, and clapping with the crowd during instrumental breaks. Even if singers know how to play an instrument, they do not play in performance since their talents as a show person are all-consuming.

10. All of my sessions with keyboard players were documented on tape and video recorder. In live presentations of this material, it was effective to show various videotaped clips where sound, picture, and dialogue combined to facilitate analysis and speculation regarding the practical and conceptual processes involved in music-making. I apologise for the inadequacies of text for communicating the same kinds of information. This dilemma has been identified and unpacked by Charles Seeger in many of his writings (see, for example Seeger 1965, also reprinted in The Garland Library of Readings in Ethnomusicology, Volume 1 (Shelemay 1992)).

11. The terms 'head' and 'top' are borrowed from my experience with jazz and popular American music. Although I do not remember my consultants using these words during this particular session, I suspect they would feel comfortable with them. Arab-American musicians use much American popular music terminology, even when they are speaking in Arabic. Words such as 'band', 'gig' and 'number' (in reference to a musical composition or song) are commonplace. The formal structures of Arab popular songs are not unlike American popular songs, they are strophic and sectional, for example A A B. The qualities of polyphony in ensembles that use synthesizers are fascinating. I treat the topic of polyphony in an article (Rasmussen 1992) and in a forthcoming manuscript.

12. I have heard a few different verbs to describe the process of changing intonation including 'retune', 'detune' and 'sharq $\vec{\imath}$, literally 'Eastern'. The use of the term 'sharq $\vec{i}$ ' in verbal discourse by musicians is especially interesting. For example, one Arab-American keyboard player told me, 'With certain scales you have to sharq $\bar{i}$ [make Eastern] the [note] $E$ and then sharqi [make Eastern] the [note] B' (Wa'el Rami, personal communication, 30 May 1995).

13. I am indirectly indebted to New York based qānūn player George Basil, whose performances I have witnessed both live and videotaped, as well as to my colleague Jane Sugarman, a fine performer of the qānūn. Comparing performance practice through one's own performance experience leads directly to questions of how musicians think about music. For example, on a qānūn, each octave may not be tuned exactly the same whereas as on a keyboard each octave is identical. Different ways of mapping out notes reflect or force different ways of thinking about maqām, especially the issue of the exact duplication of pitches in each octave. The strategies involved in modulation in Arab music is the topic of an article by Marcus (1992), and one that I hope to explore further with keyboard players.

14. That singers do not know what they are doing is a common complaint among instrumentalists who often perform for the first time with singers with whom they have never rehearsed or with someone from the audience.

15. Tom Abraham explained that he programs the intervals on his box to go up 53 cents and down 47 cents (personal communication, 12 August 1994). I am indebted to my colleague Dan Gutwien for our discussions on thought process and computer operations.

16. Incidentally, keyboard player George Musally of the New England area, said he was just as interested in acquiring the string or horn sounds from travelling keyboard players, most of them from Lebanon, as he is in copying their ' $\bar{u} d$ sample. To be able to reproduce the synthesized horns that are the signature sounds of Lebanese bands, such as those of Ragheb Alami, is a requirement for contemporary musicians.

17. I have met only two players of the mijwiz in 
the United States. I have never seen a drummer with a zambur on stage but instrument maker Abdulhamid Alwan of Milwaukee, Wisconsin is perfecting a model of the zambur. The drum is about 18 inches tall and only about 3 to 5 inches in diameter. In traditional performance practice the head is stretched by applying pressure with the thumbs to the middle until a buzz is produced when the head is struck.

18. See Racy's article for attitudes surrounding the mijwiz (1994, pp. 49-53). In an article in progress, I compare this use of the rural and the natural as organising principles in expressive culture with comparable practices in Iranian exile culture videos as discussed by Hamid Naficy (1991, 1993), who might refer to the use of these folk instruments as 'fossilized representations of home and the past' (1993, p.34).

19. 'Unplugged' refers to the commonly accepted new term for acoustic music, coined from Eric Clapton's album title and MTV (Music Television). A new search for old aesthetics is also a pattern in early (e.g., Western art) music circles with their revisionist implementation of historically informed performance practice.

\section{References}

Bakan, M., Bryant, W., Li, G. M., Martinelli, D. and Vaughn, K. 1990. 'Demystifying and classifying electronic music instruments', Selected Reports in Ethnomusicology, 8, pp. 37-63

Chambers, I. 1993. 'Travelling sounds: whose center, whose periphery?', in Otherness and the Media: The Ethnography of the Imagined and the Imaged, ed. H. Naficy and T.H. Gabriel (Langhorne, PA)

Coplan, D. 1982. 'The urbanization of African music: some theoretical observations', Popular Music 2: Theory and Method, pp. 112-29

1991. 'Ethnomusicology and the meaning of tradition', in Ethnomusicology and Modern Music History, ed. S. Blum, P.V. Bohlman and D.M. Neuman (Urbana), pp. 35-48

El-Shawan, S. 1980. 'The social-political context of al-musiqa al-'arabiyyah in Cairo, Egypt: policies, patronage, institutions and musical change (1927-1977)', Asian Music, 12/1, pp. 86-128

1984. 'Traditional arab music ensembles in Egypt since 1967: the continuity of tradition within a contemporary framework', Ethnomusicology, 28/2, pp. 271-88

Fathallah, L. 1992. 'Instruments à cordes et à clavier dans les recommandations du Congrès du Caire', Musique Arabe: Le Congrès du Caire, trans. Pierre Vigreux, proceedings of a colloquium on the documents of the first congress on Arab music in Cairo, 1932, held in Cairo in May, 1989 under the direction of Sheherazade Qassim Hassan (Cairo), pp. 99-104

Maloof, A. 1917. Music of the Orient for Piano (Brooklyn, NY)

Marcus, S.L. 1989. 'Arab music theory in the modern period', PhD dissertation, University of California at Los Angeles

1992. 'Modulation in Arab Music: documenting oral concepts, performance rules and strategies', Ethnomusicology, 36/2, pp. 171-96

Naficy, H. 1993. The Making of Exile Cultures: Iranian Television in Los Angeles (Minneapolis)

Porcello, T. 1991. 'The ethics of digital audio-sampling: engineers' discourse', Popular Music, 10/1, pp. 69-84

Proteus/3 Operation Manual 1993.

Qassim Hassan, S. 1984. 'Khishba', The New Grove Dictionary of Musical Instruments (London) p. 423

Racy, A.J. 1991. 'Historical worldviews of early ethnomusicologists: an east-west encounter in Cairo, 1932', in Ethnomusicology and Modern Music History, ed. S. Blum, P.V. Bohlman and D.M. Neuman (Urbana and Chicago) pp. 68-91

1994. 'A dialectical perspective on musical instruments: the east-mediterranean mijwiz', Ethnomusicology, 38/1, pp. 37-58

Rasmussen, A.K. 1989. 'The music of Arab Americans: performance contexts and musical transformation', The Pacific Review of Ethnomusicology, 5, pp. 15-33

1991. 'Individuality and musical change in the music of Arab Americans', PhD dissertation, University of California at Los Angeles

1992. "'An evening in the Orient": the Middle Eastern nightclub in America', Asian Music, 23/2, 66-68

Schuyler, P. 1990a. 'Hearts and minds: three attitudes toward performance practice and music theory in the Yemen Arab Republic', Ethnomusicology, 34/1, pp. 1-18

1990b. 'Music and tradition in Yemen', Asian Music, 22/1, pp. 51-72

Seeger, C. 1965. 'Preface to the critique of music', Inter-American Bulletin, 49, pp. 2-24

Shelemay, K.K. (ed.) 1992. Ethnomusicology: History, Definitions, and Scope (New York) 
Vigreux, P. 1992. 'Le congrès de musique Arabe du Caire dans la press Égyptienne (Janvier-Juin 1932)', Musique Arabe: Le Congrès du Caire, proceedings of a colloquium on the documents of the first congress on Arab music in Cairo, 1932, held in Cairo in May, 1989 under the direction of Sheherazade Qassim Hassan (Cairo), pp. 437-26

\section{Interviews}

Abbas, Abe and Abdallah. Interview with the author, 8 July 1994, Southfield, Michigan. Abraham, Tom. Interview with the author, 12 July 1994, Detroit, Michigan.

Kakka, Majid. Interviews with the author, 6, 9, 11 July 1994, Southfield, Michigan. Musally, George. Interview with the author, 11 June 1995, Foxboro, Massachusetts. Mustapha, Walid. Interview with the author, 3 July 1994, Detroit, Michigan. Rami, Wa'el. Interview with the author, 30 May 1995, Dearborn, Michigan. Shaito, Ghassan. Interview with the author, 10 July 1994, Flint, Michigan.

\section{Discography}

S. Shaheen with Faruk Tekbilek, Hassan Ishkut and Samir Khalil, Turath (Heritage) . . . Masterworks of the Middle East. CMP Records, 3006, 1991. 